\title{
FRAUD DETECTION IN FINANCIAL STATEMENTS APPLYING BENFORD'S LAW WITH MONTE CARLO SIMULATION *
}

\author{
Vladan PAVLOVIĆ - Goranka KNEŽEVIĆ - Marijana JOKSIMOVIĆ - \\ Dušan JOKSIMOVIĆ
}

(Received: 21 November 2017; revision received: 26 June 2018;

accepted: 9 July 2018)

Benford's Law is a useful tool for detecting fraud in financial statements. In this paper we test the financial item named 'Work performed by the undertaking for its own purpose and capitalised' applying this tool. The data are taken from the financial reports of all companies submitted to the Serbian Business Register Agency for the period of 2008-2013. Our conclusion shows that there is a very high probability that the frequency distribution of the second digit does not satisfy Benford's Law. In other words, it implies that certain manipulations have been usually done with the second digit of the aforementioned item in the financial statement. This research confirms our hypothesis that financial statement frauds are usually conducted using the second digit.

Keywords: Benford's Law, income statement, auditing, financial fraud, Monte Carlo simulation

JEL classification indices: C15, M41, M42, G30

* This paper is a part of the results of the Research Project No. 179001 and Project III 45003 supported by the Ministry of Education, Science and Technological Development of the Republic of Serbia.

Vladan Pavlović, corresponding author. Full Time Professor at the Faculty of Economics, University of Pristina (Kosovska Mitrovica), Serbia. E-mail: vladan.pavlovic@pr.ac.rs

Goranka Knežević, Full Time Professor at Singidunum University, Belgrade, Serbia.

E-mail: gknezevic@singidunum.rs

Marijana Joksimović, Associate Professor at Megatrend University, Belgrade, Serbia.

E-mail: joksimovicm@megatrend.edu.rs

Dušan Joksimović, Full Time Professor at the Academy of Criminal Investigation and Police Studies, Belgrade, Serbia. E-mail: dusan.joksimovic@kpu.edu.rs 


\section{INTRODUCTION}

The objective of financial statements is to provide information about the financial position, financial performance, and cash flows of an entity that is useful to a wide range of users in making economic decisions (IAS 1.9.). The financial statements must "present fairly" these facts. Fraud in financial statements can lead to losses not only for individual investors, creditors and suppliers, but can also destabilise the capital markets (Amiram et al. 2013: 1541), as well as the overall stability of global economies (Zhou - Kapoor 2011: 570).

Manipulations with accounting numbers and transactions are as old as the history of financial reporting and the roots of manipulations are traced back with the history of accounting. Based on whether the articles of the Law or accounting standards are violated, or based on a managerial intent, those manipulations can be classified as fraudulent behaviours or management of legally accepted earnings (Marai - Pavlović 2014; Ljubić - Pavlović 2016). Although there are minor variations in the definition, the Association of Certified Fraud Examiners defined a financial statement fraud as "The intentional, deliberate, misstatement or omission of material facts, or accounting data which is misleading and, when considered with all the information made available, would cause the reader to change or alter his or her judgment or decision" (Zhou - Kapoor 2011: 570). These days, globalisation is creating a central stage for large scale business frauds (Bose et al. 2011: 557). Since the growth of the internet and invention of other modern technologies, there has been a dramatic increase in fraudulent schemes, whereby financial statement fraud in particular has been rapidly increasing. Economically, financial fraud is becoming an increasingly serious problem (Ngai et al. 2011: 559) and the fraud detection has become indispensable in order to save the interests of businesses and stockholders (Bose et al. 2011: 557). Thus, financial fraud detection is an emerging topic of great importance. Detection of such fraud is traditionally conducted by financial analysts, such as certified public accountants or auditors.

Not all the items of financial statement are 'convenient' for manipulation, therefore, only some accounts are considered as high-risk ones (Smith 1964; McDaniel - Kinney 1995; Joyce 2001; Gul et al. 2003; Rose 2007; Bowlin 2011). Some items are more suitable for accounting manipulations while others can be easily spotted by auditors and tax investigators. It is commonly known that the item 'Work performed by the undertaking for its own purpose and capitalised' in financial statement is often manipulated by managers. The main reason for manipulations with this item is its effects on income statement and statement of financial position. The final benefits of these manipulations are the increase in 
revenue and higher value of assets. This in turn affects profitability ratios and decrease leverage ratios. The manipulations with this item are followed by illegal transactions in which material and semi-finished products are sold but not recognized in the accounting books. Those products and material are sold for cash by which manipulators obtain the illegal cash benefits from it. This type of transactions involves the senior executives in its execution. It is well known that the most damaging fraud inflicted on an organisation is usually executed from the senior executive level (Hake 2005; Glancy - Yadav 2011). These kinds of frauds are most difficult to detect because the managers involved in such fraudulent activities usually make the internal control systems useless for fraud detection. Even when the internal control system has been well designed, a perpetrator of a fraud is highly resourceful, knowledgeable and organised, therefore, it is reasonable to assume that the manipulation of transaction records or books of accounts would have been done with a fair amount of sophistication so as to evade detection by any of the internal control systems in place (Bhattacharya et al. 2011: 576). The complexity of a financial fraud (i.e., how well it is concealed so as to evade detection by reasonably alert internal control systems) would depend on both the level of sophistication in the manipulation of the financial records (the "Manipulation" variable) and the extent of involvement of multiple perpetrators (the "Involvement" variable) (Bhattacharya et al. 2011: 577). Fraud on the item 'Work performed by the undertaking for its own purpose and capitalised' is followed by a high level of sophisticated manipulation, which extends to the involvement of multiple perpetrators as well. So, fraud on this item is very complex for discovering.

Industries are not equally exposed to fraud. The construction industry is exposed to fraud and criminal acts in general, as well as in the case of reporting of the item 'Work performed by the undertaking for its own purpose and capitalised'. Della Porta - Vannucci (2016) identified the construction industry as an internationally recognised target for organised crime. Charbonneau - Lachance stated (2015: 122) that schemes of collusion and corruption in the awarding and management of public contracts in the construction industry link to political party financing, and infiltration activities of the organised crime are committed in this industry. Given the nature of the industry (lack of transparency, inadequate supervision of work, inability to estimate the cost of work, a complex contractual chain and a large number of transactions, the lack of adequate controls, i.e. difficulty with control and monitoring by public authorities, etc.) criminal activity is far more widespread than was originally believed. Construction projects are characterised by the following: "All these monetary transactions pave the way for the remuneration of fictitious employees, sending invoices for supplies that 
have never been received and at exorbitant prices for supplies and materials" (Charbonneau - Lachance 2015: 1261). In the construction industry, frauds committed on the item 'Work performed by the undertaking for its own purpose and capitalised' usually cannot be detected at all. Quality and quantity of material used and reported with the section of work in process capitalised are subject to expert evaluations which can be done only in certain stages of production. For example, in the construction industry it is not easy to detect quality and quantity of cement or armature used for the bedrock or to detect the real labour cost. In other industries, committing fraud and using manipulative techniques with the item 'Work performed by the undertaking for its own purpose and capitalised' can be detected, but this job cannot be done without huge effort and knowledge invested. Manipulations on the item involve managerial accountant to issue improper internal documents regarding the usage of material or labour cost in the process. The transactions are partially fictitious because not all the recorded material has been used in the production of final or semi-finished products, as well as the works performed by the employees are also falsely recorded on these internal documents.

There is a limited possibility to detect this fraud, as the analysis committed on this item has not been investigated by academicians and other legal authorities. Auditors do not consider this item as suspicious because they cannot obtain sufficient audit evidence to support their opinion. This accounting item has rarely been used as a subject of academic articles (Spasić 2016) and accounting regulation (Commission regulation No 250/2009; Fourth Council Directive 78/660/EEC).

In practice, financial statement fraud might involve: (1) manipulation of financial records, (2) intentional omission of events, transactions, accounts, or other significant information from which financial statements are prepared, or (3) misapplication of accounting principles, policies, and procedures used to measure, recognise, report, and disclose business transactions (Zhou - Kapoor 2011: 570). Tools for financial fraud detection include Benford's Law, data analysis techniques like regression, discriminant analysis, clustering, neural networks, decision trees, Bayesian belief networks, support vector machines, self-organising maps, among others (Bose et al. 2011: 557). However, there is no agreement on which data features and techniques are best for detection. The usage of Benford's Law or neural network systems has been highlighted as the consequence of malfunction of traditional analytical procedures which have yielded limited success in identifying fraud (Hogan et al. 2008: 241). Therefore, in this paper we apply the Benford's Law to detect fraud within the item 'Work performed by the undertaking for its own purpose and capitalised'. 


\section{LITERATURE REVIEW ON BENFORD'S LAW}

Benford (1938) and Newcomb (1881), independently, discovered what we today are referring (a little bit inaccurate) as Benford's Law. A polymath, named Simon Newcomb, primarily an astronomer but also sometimes an editor of the American Journal of Mathematics proposed a law of the probability of appearance of the first digit. In his short paper, Newcomb called the phenomenon that he had noticed as the "Law of frequency" and "Law of the probability of occurrence of numbers" (1881: 39, 40). However, as Raimi (1976: 522) states, "even Newcomb implied that the observation giving rise to the Benford's Law was an old one his day". Nevertheless, as it is known, until Newcomb's paper, the term "Law of frequency" seems to have been used in two distinct senses by mathematical writers, which was leading to confusion (McAlister 1879: 337), but not in the meaning that Newcomb has described in this phenomenon. The formulated expression showing the frequency of first digits was surprising both to Newcomb and his colleagues. But, it is interesting that the finding was promptly forgotten! (Stoessiger 2013: 29) The Law was rediscovered 57 years later by Benford (1938), who may well have been unaware that Newcomb had already formulated it, having in mind that Newcomb's article went unnoticed. Unlike his predecessor, Benford vigorously pursued this phenomenon and published his findings in a number of academic papers. Thus, the phenomenon came to be known as "Benford's Law", though Benford called the phenomenon as "The Law of Anomalous Number" and "The Logarithmic Law" (1938: 551). Unlike earlier precedent which did not develop the law from any insight into the number system, Benford spent several years in gathering data (Hill 1998: 358) and proved that, in certain circumstances, the distribution of the leading digit, $\mathrm{D}$, in a collection of numerical data is given by the logarithmic formula (Stoessiger 2013: 29). Similarly as Newcomb, Benford was so surprised with the noticed distribution which fit the logarithm law of probability that he called this phenomenon as 'The law of anomalous numbers'. This particular logarithmic distribution of the first digits, while not universal, is so common and yet so surprising at first glance that it attracts interest from a varied literature, among the authors of which are mathematicians, statisticians, economists, engineers, physicists and amateurs (Raimi 1976: 522). This logarithm law of probability is much later known as Benford's Law, by which it is widely known today.

After several decades of its re-discovery by Benford, the term "first digit law", or "first digit phenomenon" was mostly used (Moser - Macon 1950; Ralph - Raimi 1969; Bumby - Ellentuck 1969; Cohen 1976; Hill 1988), or sometimes it is mentioned as "initial digit law/ phenomenon" (Gini 1957; Herzel 1957; Pinkham 1961; Flehinger 1966; Duncan 1969; Whitney 1972; Davis 1976), and rarely as 
"leading digit law" (Diaconis 1973) or even "harmony law" (Furlan 1946). In some of the above mentioned papers, Bendford's name was not even used. The name of this law which highlights the phenomenon of the appearance of the first digit is certainly not appropriate. As Hill (1998: 359) points out, "there is also a general significant digit law that includes not only the first digits but also the second (which may be 0 ), all higher significant digits and even the joint distribution of digits." It seems to be very important today when few researches point out that the first digit should not be used for financial fraud detection. The Benford's Law literature has progressed from an 18-page review in 1976 by Raimi. At the time of Raimi's article on Benford's Law in Scientific America, the significantdigit phenomenon was thought to be merely a mathematical curiosity within reallife applications, and without a satisfactory mathematical explanation (Hill 1998: 363). Starting from the second half of the 80 s of the last century, this law is being used more often in the consistency analysis of the numerical data expressed in various social and natural phenomena. Nowadays, the theoretical analysis of this law in the area of finding a better mathematical basis and its implementation is still a current issue.

The Benford's Law gets wide popularity at the end of the $20^{\text {th }}$ century with its application in computer sciences, biological sciences, physics, astrophysics, socio-physics, econophysics and hydrogeology. Today, the logarithm law of probability can rarely be found under any different name than Benford's Law. This Law is widely applied in the investigation of data manipulation by researchers in finance and economics. But, since Nigrini's Ph.D. thesis (2017) in accounting based on an analogous idea using Benford's Law, there is a growing professional interest on the application of Benford's Law and "digit analysis" in financial fraud detection (Bhattacharya et al. 2011: 576; Bose et al. 2011: 557). Today, it is broadly considered that the law can be applied as a relevant approach, i.e., it is useful to apply Benford's tests to detect fabricated or falsified scientific data as well as fraudulent financial data. The application of the Law is also widely recommended by the forensic services of respectable auditing houses, like KPMG. Gomes da Silva - Carreira (2013) have even developed an audit sample selection method based entirely on the deviations from the expected proportions of the Benford's Law. It seems that Benford-based sampling would, therefore, be useful for detecting misstatements in transactions, such as Journal entries; and balances, such as Customer balances in checking and savings accounts; Accounts receivable and credit card balances; Inventory line items (quantity multiplied by unit cost) in a perpetual inventory environment; and Vendor and supplier amounts due. Nigrini (2017) summarised the applications of the Law in the accounting literature such as: threshold; fraud detection; audit opinion; comparative fraud 
risk; and other applications, like assessing the realism of the numbers in accounting textbooks.

Besides using for identification of falsely created data in corporations' financial statements, the Benford's Law is most frequently used for detecting manipulations in the stock markets. But this does not exhaust the application of the Law in economics and finance. Ausloos et al. (2017) have recently assessed the possible manipulation in the tax-income of the citizens in Italy through accounting city aggregated income tax reports from all Italian regions. The investigation of the tax evasion in Italy using the concept of the Law has also been done by Mir et al. (2014). Martin (2017) has recommended this Law for detecting bidding fraud in the construction industry, Tóth - Hajdu (2016) used it for analysing the contract price distortion, while Clippe - Ausloos (2012) investigated a religious movement in financial reports using the concept. The Benford's Law has also been used for verifying the (non)reliability of macroeconomic data (Shi et al. 2018; Michalski - Stoltz 2013), i.e. for detecting fraudulent data that governments are publishing. Deleanu (2017: 1) claims that despite the assumption that government's cheating would be unmasked instantly, indicators of compliance and efficiency in combating money laundering, collected by EUROSTAT, are plagued with some shortcomings.

The Benford's Law is based on the fact that only naturally occurring numbers should follow a particular pattern, more pathetically: the Law can be regarded as a veritable signature of Nature. As Kumar - Bhattacharya (2007: 82) stated that humans are accustomed to counting arithmetically, as opposed to Nature that counts geometrically, then if the numbers have been artificially concocted, they will not fit with the naturally logarithmic distribution of the numbers. This implies that the human brain wrongly assumes that natural numbers are distributed linearly. Thus, when it comes to fraudulent manipulation of accounts, an employee making up a series of false figures to boost his expenses will try to make them look "natural" by spreading the first digits evenly between 0 and 9 . His figures will not of course fit Benford's Law, and so may be detected. Concocted numbers used to "balance the books" in more complex frauds are also essentially non-natural, because the ultimate objective is to correct the irregularities created by misappropriation of funds (Kumar - Bhattacharya 2007: 82). Under a standard double-entry book-keeping system, the figures that are made up to essentially "plug the gaps" caused by fraud can result in differences in the observed 1st and 2nd-digit frequencies from those predicted by Benford's Law (Bhattacharya et al. 2011: 577). The Law is not affected by the magnitude or 'history' of a transaction and therefore can be very effective in detecting "bleeding frauds", where small amounts are fraudulently siphoned off over a period of time via dubious transac- 
tions without alerting internal controls. Traditional review procedures while being able to identify frauds that involve a single high-value transaction may not, however, be effective in detecting such bleeding frauds. The Law might detect "invented balance amounts" as well as fictitious amounts where a large proportion of the population is fictitious (Nigrini 2017: 41).

However, it seems that some fraudsters started to expect that the auditors use the Benford's Law as a "red flag for fraud" (Nigrini 2017: 29) and fabricate a falsified data which are in line with the Law. Hence, Diekmann (2007) argues that the first digit should not be tested. If second and later digits deviate from the Benford's distribution, this deviation may yield an indication that the data have been fabricated. His research indicates that the checks for digit-preference anomalies should focus less on the first (i.e. leftmost) and more on the later digits. Joenssen (2013) also recommends the use of an additional, third or fourth significant digit whereby the ideal number may be context dependent. Using multiple digits makes the usage of statistics reserved for continuous data more plausible, paving the way for the development of further goodness-of-fit tests.

\section{DEFINITIONS OF BENFORD'S LAW AND THEIR MUTUAL EQUIVALENCY}

It is commonly understood that for any base where $B>1$ any positive real number $(x>0, x \in R)$ can be expressed as

$$
x=M_{B}(x) \cdot B^{k}
$$

where $k \in Z$, a $M_{B}(x) \subset[1, B)$. The number $M_{B}(x)$ will denote mantissa of the number $x$. We can conclude that the following equation is proven to be true (Joksimović et al. 2017)

$$
M_{B}(x)=\frac{x}{B^{k}}=\frac{x}{B^{\left[\log _{B} x\right]}}=\frac{B^{\log _{B} x}}{B^{\left[\log _{B} x\right]}}=B^{\log _{B} x-\left[\log _{B} x\right]}
$$

where $\left[\log _{B} x\right]$ denotes the whole part of the number $\log _{B} x$, or the greatest integer less than or equal to $\log _{B} x$.

In scientific practice we can find two mutually equivalent definitions of Benford's Law: as a function of probability distributions of mantissa numerical data and for the joint probability distribution of representing first $\boldsymbol{k}$ digits of significant numerical data (Joksimović et al. 2017).

Definition 1. (Benford's Law for the function of the probability distribution of mantissa) 
Random variable $\boldsymbol{X}$, whose realisations have only positive values in the base $B>1$, is recognised under Benford's Law if and only if the function of the probability distribution of a random variable determined by the mantissa of the random variable $\boldsymbol{X}, \boldsymbol{M}(\boldsymbol{X})$, in that base is recognised under the following logarithm law:

$$
P\left(M_{B}(x) \leq m\right)=\log _{B} m
$$

where $m \in[1, B)$.

Definition 2. (Benford's Law for the joint probability distribution of leading $k$ digits in the numbers)

Random variable $\boldsymbol{X}$, whose realisations have only positive values in the base $B>1$, follows Benford's Law if and only if the joint probability distribution of first $\boldsymbol{k}$ significant digits of their realisation, $\left(C_{j}\right)_{j=1,2, \ldots, k},\left(k \in N^{*}\right)$, satisfies the following law:

$$
P\left(C_{1}=c_{1}, C_{2}=c_{2}, \ldots, C_{k}=c_{k}\right)=\log _{B}\left(1+\frac{1}{\sum_{i=1}^{k} B^{k-i} c_{i}}\right)
$$

where $c_{1} \in(1,2, \ldots, B-1), c_{j>1} \in(0,1,2, \ldots, B-1)$.

At first glance, it seems that Definition 2 can be used only for the discrete random variables, but this is not correct, because the condition is that $\boldsymbol{k}$ belongs to the unlimited set of positive integers, going to the infinity $\left(k \in N^{*}\right)$.

Also, we can notice that the following expression is valid because of the continuity:

$$
\begin{aligned}
P\left(M_{B}(x) \leq m\right)= & P\left(M_{B}(x)<m\right)+P\left(M_{B}(x)=m\right)=P\left(M_{B}(x)<m\right), \\
& \text { because it is } P\left(M_{B}(x)=m\right)=0 .
\end{aligned}
$$

Mutual equivalence of these definitions can be proven (Appendix). Some characteristics of the random variable that satisfies Benford's Law are presented by Joksimović et al. (2017) and Joksimović - Knežević (2016). Numerical and graphical analysis of random variable that satisfies the Law shows that starting with the fourth significant digit and onward, in all of the bases (digits $C_{k>4}$ ), almost all is uniformly distributed, and we can say that for the probable distribution of the third digit. Therefore, the implementation of the Law in practice is constrained to the analysis of the probability distribution of the first two significant numbers, and only sometimes the analysis involves the third significant number in the set of numerical data. 


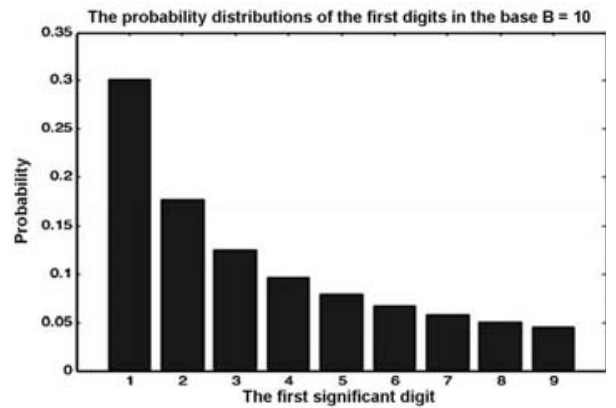

Source: Joksimović et al. (2017).

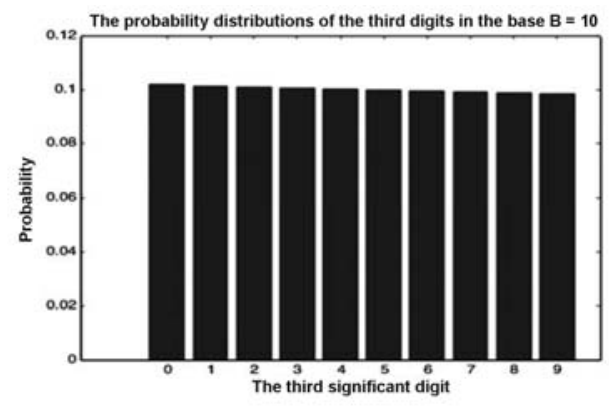

Source: Joksimović et al. (2017).

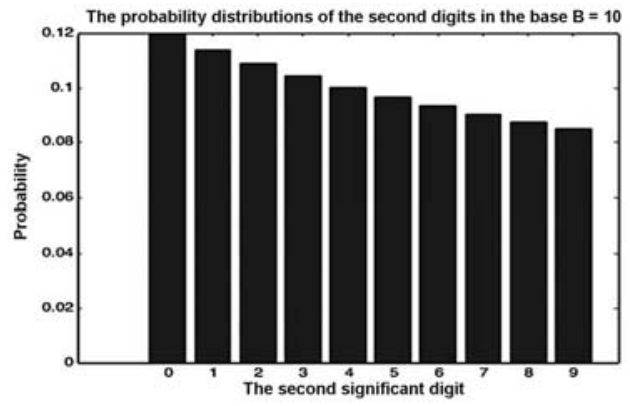

Source: Joksimović et al. (2017).

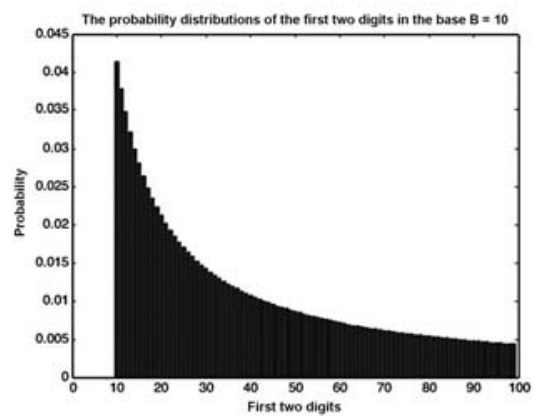

Source: Authors' own figure

Figure 1. The probability distributions of the first, second, third, and the first two digits in the base $\mathrm{B}=10$

The graphics of the probability distributions of the first, second, third, and the combination of the first two digits of random variable satisfying Benford's Law, in the base $\mathrm{B}=10$, are given above.

\section{DATA AND METHODS}

The data considers the item 'Work performed by the undertaking for its own purpose and capitalised' reported in the Income Statement (Position 203) of Serbian companies. Serbian companies submit their financial statements on a regular basis (once a year) to the Serbian Business Registers Agency (SBRA). The data are collected for the period of 2008-2013. We took 1001 observations of this item in the reported period, while only 327 had non-zero number reported within the item. 
There are many tests developed and used for the testing of Benford's Law on the numerical data (test of the Mean Absolute Deviation, Pearson $\chi^{2}$ test, Kolmogorov - Smirnov test (KS test), Kuiper test, Z-test, Test of the sum invariance, Test of the factors of distortion, Second level test, Test of doubling the digits, Test the last two digits, among others). With the help of the above mentioned tests, we investigate whether the significant numbers of the set comprising of $\mathrm{N}$ numerical data $X=\left\{x_{i} \mid i=1,2, \ldots, N\right\}$ deviate from Benford's Law. All of these tests are constructed under the method of statistical hypothesis such as the following:

H0: Significant numbers of the sample satisfy Benford's Law and an alternative hypothesis that is accepted or rejected depending on the nature of the test.

H1: Significant numbers of the sample do not satisfy Benford's Law.

For a certain level of probability distributions of the test $\alpha$ we accept or reject the alternate hypothesis H1. If we accept the hypothesis then we believe in it with the probability of $1-\alpha$, and if we reject it, we do not believe in this hypothesis with the probability of $1-\alpha$. Not accepting the hypothesis does not mean that $\mathrm{H} 0$ is accepted, but implies that we are not quite sure about the alternate hypothesis H1. Consequently, more valuable information regarding $p$ value for each test is used, because $p$ value shows about our belief in the hypotheses, such as belief in the alternate hypothesis $\mathrm{H} 1$ with the probability of $1-p$, and in the null hypothesis H0 with the probability $p$.

Based on the result of $p$ value we can decide the following: we accept the alternate hypothesis $\mathrm{H} 1$ as accurate when $p$ value is very small, or we accept the null hypothesis $\mathrm{H} 0$ as true if $p$ value is high, or we cannot determine the validity of any of the hypothesis with the usage of certain test because $p$ value is neither significantly high nor significantly low.

In this paper we are going to describe and use Pearson $\chi^{2}, \mathrm{KS}$ test and Kuiper test with Stephens' correction (Stephens 1970) for the first, second and also for the first two digits combined. For each of these tests, $p$ value will be determined by Monte Carlo simulation.

\section{Pearson $\chi^{2}$}

Pearson $\chi^{2}$ test denote $\sum_{i=1}^{k} \frac{\left(O_{i}-E_{i}\right)^{2}}{E_{i}} \sim \chi_{k-1}^{2}$, where
Oi - sample frequency
Ei - expected frequency

The appearance of the characteristics of the set is classified into k classes. In this analysis, the number of classes is equal to the number of digits $(k=9$ for the 
analysis of the first digit, $\mathrm{k}=10$ for the analysis of the second digit, and $\mathrm{k}=90$ for the analysis of the first two digits), and this test is then:

$$
\begin{gathered}
C h i_{D 1}=N \cdot \sum_{c_{i}=1}^{9} \frac{\left(P\left(C_{1}=c_{i}\right)-P\left(C_{1}=c_{i}\right)\right)^{2}}{P\left(C_{1}=c_{i}\right)} \sim \chi_{8}^{2} \\
C h i_{D 2}=N \cdot \sum_{c_{i}=0}^{9} \frac{\left(P\left(C_{2}=c_{i}\right)-P\left(C_{2}=c_{i}\right)\right)^{2}}{P\left(C_{2}=c_{i}\right)} \sim \chi_{9}^{2} \\
C h i_{D 1 D 2}=N \cdot \sum_{c_{i}=1}^{9} \sum_{c_{j}=0}^{9} \frac{\left(P\left(C_{1}=c_{i}, C_{2}=c_{j}\right)-P\left(C_{1}=c_{i}, C_{2}=c_{j}\right)\right)^{2}}{P\left(C_{1}=c_{i}, C_{2}=c_{j}\right)} \sim \chi_{89}^{2}
\end{gathered}
$$

\section{Kolmogorov - Smirnov test (KS test)}

Approximate (not completely theoretical) KS test

In this test we compute D coefficient for the first, second and for the combination of the first two digits:

$$
\begin{gathered}
D_{D 1}=\max |c d P B D 1(i)-c d \operatorname{Ver} D 1(i)|, i=1,2, \ldots \ldots, 9 \\
D_{D 2}=\max |c d P B D 2(i)-c d \operatorname{Ver} D 2(i)|, i=0,1,2, \ldots, 9 \\
D_{D 1 D 2}=\max |\operatorname{cdPBD} 1 D 2(i)-c d \operatorname{Ver} D 1 D 2(i)|, i=10,11,12, \ldots, 99 .
\end{gathered}
$$

\section{Completely theoretical KS test}

In this test we compute $\mathrm{D}_{\mathrm{KS}}$ coefficient for the first, second and the combination of the first two digits:

$$
\begin{gathered}
D_{K S_{D 1}}=\max ((c d P B D 1(i)-c d \operatorname{Ver} D 1(i-1)),(c d V e r D 1(i)-c d P B D 1(i))), i=1,2, \ldots, 9 \\
D_{K S_{D 2}}=\max ((c d P B D 2(i)-c d \operatorname{Ver} D 2(i-1)),(c d V e r D 2(i)-c d P B D 2(i))), i=0,1,2, \ldots, 9 \\
D_{K S_{D 1 D 2}}=\max ((c d P B D 1 D 2(i)-c d \operatorname{VerD} 1 D 2(i-1)),(c d V e r D 1 D 2(i)-c d P B D 1 D 2(i))), \\
i=10,11,12 \ldots, 99 .
\end{gathered}
$$




\section{Kuiper test with Stephens correction}

Approximate (not completely theoretical) Kuiper test with Stephens' correction

In this test we calculate $\mathrm{V}$ coefficient for the first, second and the combination of the first two digits:

$$
\begin{aligned}
& V_{D 1}=(\max (c d P B D 1(i)-c d \operatorname{Ver} D 1(i))+\max (c d \operatorname{Ver} D 1(i)-c d P B D 1(i))), \\
& *\left(\sqrt{N}+0.155+\frac{1}{\sqrt{N}}\right) \\
& i=1,2, \ldots 9 \text {; } \\
& V_{D 2}=(\max (c d P B D 2(i)-c d \operatorname{VerD} 2(i))+\max (c d \operatorname{VerD} 2(i)-c d P B D 2(i))) \\
& *\left(\sqrt{N}+0.155+\frac{1}{\sqrt{N}}\right) \\
& i=0,1,2, \ldots 9 \text {; } \\
& V_{D 1 D 2}=(\max (c d P B D 1 D 2(i)-c d \operatorname{VerD1D2}(i))+\max (c d \operatorname{VerD1D2}(i)-c d P B D 1 D 2(i))) \\
& *\left(\sqrt{N}+0.155+\frac{1}{\sqrt{N}}\right) \\
& i=10,11,12, \ldots 99 \text {. }
\end{aligned}
$$

Completely theoretical Kuiper test with Stephens' correction

In this test we calculate $\mathrm{V}_{\text {Kuiper }}$ coefficient for the first, second and the combination of the first two digits:

$$
\begin{gathered}
D_{\text {plus } D 1}=\max (c d V \operatorname{Vr} D 1(i)-c d P B D 1(i)) \\
D_{\text {minus } D 1}=\max (c d P B D 1(i)-c d \operatorname{Ver} D 1(i-1)) \\
V_{\text {Kuiper } 11}=\left(D_{\text {plus } D 1}+D_{\text {minus } D 1}\right) *\left(\sqrt{N}+0.155+\frac{1}{\sqrt{N}}\right), i=1,2, \ldots, 9 ; \\
D_{\text {plus } D 2}=\max (c d V e r D 2(i)-c d P B D 2(i)) \\
D_{\text {minus } D 2}=\max (c d P B D 2(i)-c d \operatorname{Ver} D 2(i-1)) \\
V_{\text {KuiperD2 }}\left(D_{\text {plus } D 2}+D_{\operatorname{minus} D 2}\right) *\left(\sqrt{N}+0.155+\frac{1}{\sqrt{N}}\right), i=0,1,2, \ldots, 9 ; \\
D_{\text {plus } D 1 D 2}=\max (c d V e r D 1 D 2(i)-c d P B D 1 D 2(i)) \\
D_{\text {minus } D 1 D 2}=\max (c d P B D 1 D 2(i)-c d \operatorname{Ver} D 1 D 2(i-1))
\end{gathered}
$$




$$
V_{\text {KuiperD1D2 }}=\left(D_{\text {plus } 1 D 2}+D_{\text {minus } 1 D 2}\right) *\left(\sqrt{N}+0.155+\frac{1}{\sqrt{N}}\right), i=10,11,12, \ldots, 99
$$

In all the above mentioned tests, cdPBD1, cdPBD2 and cdPBD1D2 are cumulative distribution functions of the theoretical Benford's data where the probability of appearance of the first, second and the combination of the first two digits are given in the formula (1), while cdVerD1, cdVerD2 and cdVerD1D2 are cumulative distribution functions of the data set that we analyse, whose probability of the first, second and the first two digits together are calculated as relative frequencies of showing those digits in the drawn sample.

\section{Monte Carlo simulation in determining $p$ value}

The testing sample consists of $\mathrm{N}=327$ data in the set.

In the first step, we calculated the above mentioned parameters ChiD1, ChiD2, ChiD1D2, DD1, DD2, DD1D2, DKS_D1, DKS_D2, DKS_D1D2, VD1, VD2, VD1D2, VKuiperD1, VKuiperD2, VKuiperD1D2 for the tested sample.

After that we repeat the following procedure 100 times:

- We formulated Benford's dataset of $\mathrm{N}=327$ data 10000 times using $\left[10^{U}\right]$, where with the [ ] we denote the whole part of the number and where $U$ is uniformly distributed within the interval $(0,1)$, i.e. $U \sim U(0,1)$.

- We calculate relative frequencies of appearance of Benford's data streams formed from 10000 , with $\mathrm{N}=327$ for which the calculated parameters ChiD1, ChiD2, ChiD1D2, DD1, DD2, DD1D2, DKS_D1, DKS_D2, DKS_D1D2, VD1, VD2, VD1D2, VKuiperD1, VKuiperD2, VKuiperD1D2 are bigger than or equal to the values that we got for the tested sample, or those that we got as a result from the first step. The same procedure was done for each of the above mentioned parameters individually. Those parameters are considered as $p$ values for each of the tests used in the first simulation.

- As we repeated the procedure 100 times, for each $p$ value we have 100 of its simulated values. For the exact $p$ value we use the arithmetic mean of $100 p$ values and for all of these exact $p$ values we find standard deviation of $p$ value, with the $99 \%$ of confidence interval and $95 \%$ of confidence interval for the $p$ value, respectively, using 100 values that we got from the simulation for each of them. 


\section{DATA ANALYSIS}

Using Monte Carlo simulation we get the following results presented in Tables $1-4$.

Table 1. Calculated values for the sample tested

\begin{tabular}{l|c|c|c}
\hline & First digit D1 & Second digit D2 & First two digits D1D2 \\
\hline$C h i$ & 5.4481 & 13.0080 & 105.1986 \\
\hline $\mathrm{D}$ & 0.0205 & 0.0386 & 0.0279 \\
\hline $\mathrm{D}_{\mathrm{KS}}$ & 0.3010 & 0.1223 & 0.0441 \\
\hline $\mathrm{V}$ & 0.5665 & 1.3890 & 0.9096 \\
\hline $\mathrm{V}_{\text {Kuiper }}$ & 5.8811 & 2.9439 & 1.3172 \\
\hline
\end{tabular}

Table 2. $p$ Value for testing the first digit (D1)

\begin{tabular}{l|c|c|c|c}
\hline & $\boldsymbol{p}$ value & $\begin{array}{c}\text { Standard deviation } \\
\boldsymbol{p} \text { value }\end{array}$ & $\begin{array}{c}95 \% \text { confidence } \\
\text { interval } \boldsymbol{p} \text { value }\end{array}$ & $\begin{array}{c}99 \% \text { confidence } \\
\text { interval } \boldsymbol{p} \text { value }\end{array}$ \\
\hline Chi $\mathrm{D} 1$ & 0.7092 & 0.0040 & $0.7039-0.7154$ & $0.6996-0.7186$ \\
\hline $\mathrm{D}_{\mathrm{D} 1}$ & 0.8678 & 0.0033 & $0.8632-0.8727$ & $0.8599-0.8752$ \\
\hline $\mathrm{D}_{\mathrm{KSD1}}$ & 1 & 0 & $1-1$ & $1-1$ \\
\hline $\mathrm{V}_{\mathrm{D} 1}$ & 0.8249 & 0.0035 & $0.8194-0.8292$ & $0.8174-0.8351$ \\
\hline $\mathrm{V}_{\text {KuiperD1 }}$ & 0.4843 & 0.0048 & $0.4766-0.4914$ & $0.4728-0.4929$ \\
\hline
\end{tabular}

Table 3. $p$ Value for testing second digit (D2)

\begin{tabular}{l|l|c|c|c}
\hline & $\boldsymbol{p}$ value & $\begin{array}{c}\text { Standard deviation } \\
\boldsymbol{p} \text { value }\end{array}$ & $\begin{array}{c}95 \% \text { confidence } \\
\text { interval } \boldsymbol{p} \text { value }\end{array}$ & $\begin{array}{c}99 \% \text { confidence } \\
\text { interval } \boldsymbol{p} \text { value }\end{array}$ \\
\hline Chi $\mathrm{D} 2$ & 0.1617 & 0.0038 & $0.1556-0.1673$ & $0.1548-0.1691$ \\
\hline $\mathrm{D}_{\mathrm{D} 2}$ & 0.4185 & 0.0048 & $0.4112-0.4251$ & $0.4041-0.4279$ \\
\hline $\mathrm{D}_{\mathrm{KSD} 2}$ & 0.5566 & 0.0051 & $0.5488-0.5645$ & $0.5479-0.5686$ \\
\hline $\mathrm{V}_{\mathrm{D} 2}$ & 0.0530 & 0.0023 & $0.0498-0.0567$ & $0.0485-0.0579$ \\
\hline $\mathrm{V}_{\mathrm{KuiperD2}}$ & 0.3211 & 0.0043 & $0.3142-0.3273$ & $0.3111-0.3289$ \\
\hline
\end{tabular}

Table 4. $p$ Value for testing the combination of the first two digits (D1D2)

\begin{tabular}{l|c|c|c|c}
\hline & $\boldsymbol{p}$ value & $\begin{array}{c}\text { Standard deviation } \\
\boldsymbol{p} \text { value }\end{array}$ & $\begin{array}{c}95 \% \text { confidence } \\
\text { interval } \boldsymbol{p} \text { value }\end{array}$ & $\begin{array}{c}99 \% \text { confidence } \\
\text { interval } \boldsymbol{p} \text { value }\end{array}$ \\
\hline ChiD1D2 & 0.1211 & 0.0035 & $0.1158-0.1265$ & $0.1132-0.1286$ \\
\hline $\mathrm{D}_{\text {DID2 }}$ & 0.8998 & 0.0029 & $0.8954-0.9039$ & $0.8943-0.9062$ \\
\hline $\mathrm{D}_{\text {KSD1D2 }}$ & 0.7911 & 0.0042 & $0.7842-0.7971$ & $0.7815-0.8005$ \\
\hline $\mathrm{V}_{\text {D1D2 }}$ & 0.7703 & 0.0043 & $0.7637-0.7775$ & $0.7601-0.7794$ \\
\hline $\mathrm{V}_{\text {KuiperD1D2 }}$ & 0.7616 & 0.0045 & $0.7546-0.7684$ & $0.7500-0.7705$ \\
\hline
\end{tabular}

Sources: Authors' calculations. 
The above results show the following facts for the analysed data:

First digit:

- DKSD1 test is completely unusable for the analysis of the probability distribution of the first digit,

- according to DD1 and VD1 tests, the first digit probably satisfies Benford's Law,

- ChiD1 and VKuiperD1 tests cannot give the reliable answer on the question of probability distribution of the first digit.

Second digit:

- according to VD2 test, the second digit does not follow Benford's law with the probability level $\alpha=0.053$ ( $p$ value $=0.053$ ),

- according to ChiD2 test, the second digit with high possibility does not conform with Benford's Law,

- DD2, DKSD2 and VKuiperD2 tests cannot give reliable answer regarding the question of probability distribution of the second digit.

Combination of the first two digits:

- according to ChiD1D2 test, the first two digits taken together do not possibly satisfy Benford's Law with the probability level of $\alpha=0.1211$ ( $p$ value $=0.1211$ ),

- DD1D2, DKSD1D2, VD1D2 and VKuiperD1D2 tests cannot give reliable answer regarding the question of the probability distribution of the combination of the first two digits.

With big certainty we can give the following general conclusion: probability distribution of the second digit does not satisfy Benford's Law and because of that we cannot accept the alternate hypothesis $H 1$ for the analysed dataset, taking into consideration the additional statement that certain manipulations (intentional or unintentional) are done with the second digit only.

The graphics of the probability distributions of the first, second, third, and the combined first two digits for the analysed dataset are shown in Figure 2.

\section{CONCLUSIONS}

In this paper we try to follow the path opened by Nigrini. We have tested the conformity of the value of the item 'Work performed by the undertaking for its own purpose and capitalised' with the Benford's Law, because it is well known in the accounting world that this item is very suitable for upward manipulations. In order to precisely determine the value of this item, one requires the engagement of experts and forensic work done by forensic accountants in order to detect fraudulent behaviour of managers, accountants and employees. That is the main reason why frauds are rarely detected on this accounting item even when the biggest 

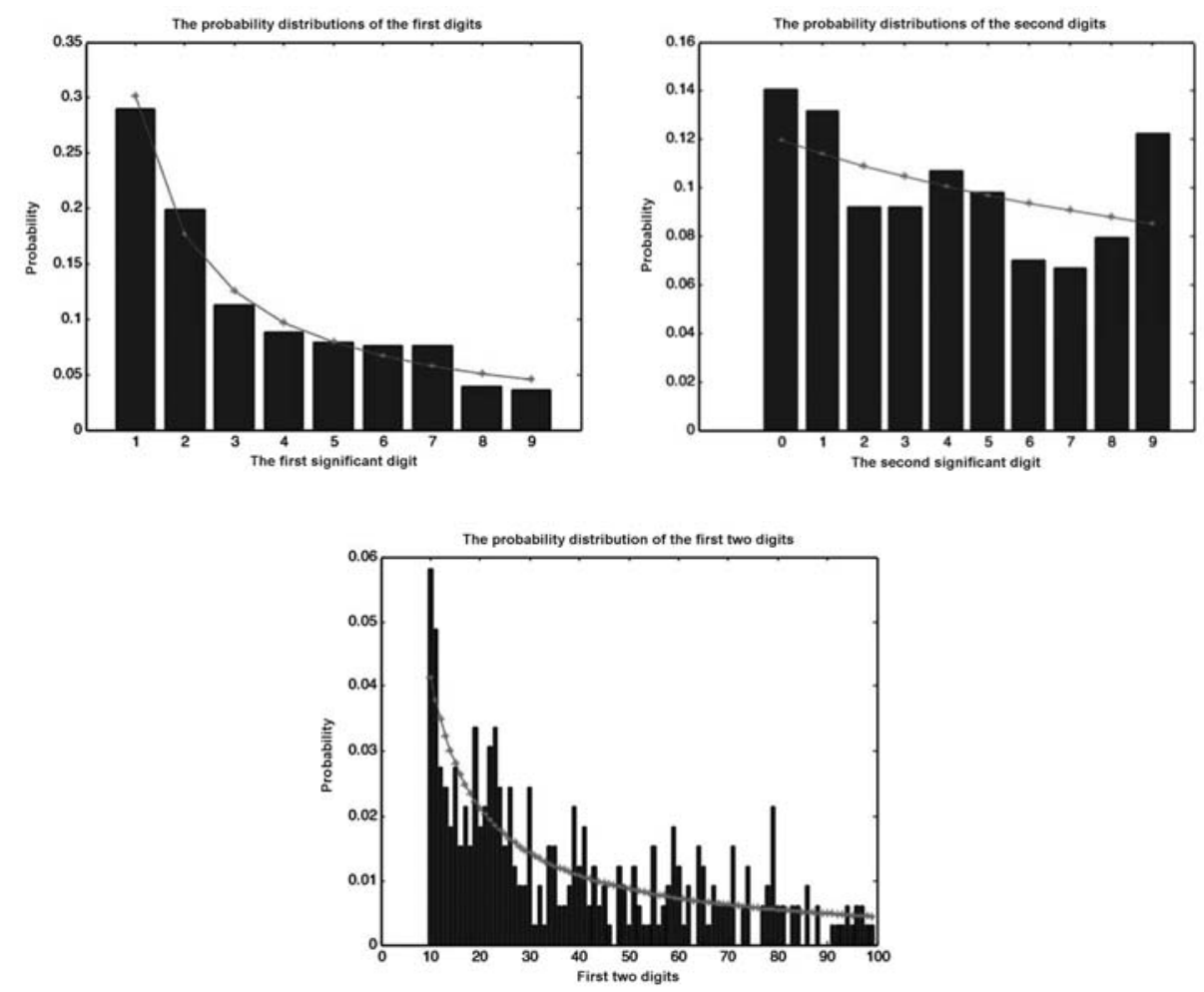

Figure 2. The probability distributions of the first, second and the combination of the first two digits

corporate accounting scandals happened. On the other hand, the external auditors' work does not comprise the activities conducted for the purpose of detecting fraud, while forensic accountants are also limited inasmuch as the involvement of management and managerial accountants eliminates the possibility to obtain additional internal evidence to support the charges against them.

Testing the conformity of this item with Benford's Law using Monte Carlo simulation shows that the first digit satisfies Benford's Law with high probability, but manipulations are done with the second digit. Namely, DD1 and VD1 tests show that the first digit follows Benford's Law. ChiD2 test with $p$ value $=0.167$ shows that the second digit probably does not conform to the Law; and according to VD2 test, the second digit also does not satisfy the Law with the $p$ value $=$ 0.053. DD2, DKSD2 and VKuiperD2 tests cannot give a reliable answer regarding the frequency distribution of the second digit. Our research supports Diekmann's statement (2007) that using a Benford's test for the first digits would provide 
misleading results when financial frauds are investigated. Our results support the idea that financial statement manipulations are done with the second digit.

The mentioned results do not come as a surprise because manipulations with the first digit will imply the financial fraud investigation to be opened and confidence in financial statements will probably be eroded.

Although, as the consequence of very difficult and painstaking job to prove the manipulations and frauds committed with these transactions, manipulations with the second digit do not imply auditors to investigate deeper on this item or to ask a specialist to be engaged in such auditing work. However, the same cannot be said if the manipulations are done with the first digit. As a consequence of conformity of the first digit with Benford's Law and the second digit's non-conformity with this Law, ChiD1D2 test shows that the combination of the first two digits very probably does not meet the requirement of the Law (with the $p$ value $=0.1211$ ). It should be kept in mind that the nature of production or the specificity of the industry itself does not give room for any company to manipulate with this item or to obtain big benefits from manipulation.

\section{REFERENCES}

Amiram, D. - Bozanic, Z. - Rouen, E. (2015): Financial Statement Errors: Evidence from the Distributional Properties of Financial Statement Numbers. Review of Accounting Studies, 20(4): $1540-1593$.

Ausloos, M. - Cerqueti, R. - Mir, T. A. (2017): Data Science for Assessing Possible Tax Income Manipulation: The Case of Italy. Chaos, Solitons - Fractals, 104: 238-256.

Benford, F. (1938): The Law of Anomalous Numbers. Proceedings of the American Philosophical Society, 78(4): 551-572.

Berger, A. - Hill, T. P. (2011): A Basic Theory of Benford's Law. Probability Surveys, 8: 1-126.

Bhattacharya, S. - Xu, D. - Kumar, K. (2011): An ANN-Based Auditor Decision Support System Using Benford's Law. Decision Support Systems, 50(3): 576-584.

Bose, I. - Piramuthu, S. - Shaw, M. J. (2011): Quantitative Methods for Detection of Financial Fraud. Decision Support Systems, 50(3): 557-558.

Bowlin, K. (2011): Risk-Based Auditing, Strategic Prompts, and Auditor Sensitivity to the Strategic Risk of Fraud. The Accounting Review, 86(4): 1231-1253.

Bumby, R. - Ellentuck, E. (1969): Finitely Additive Measures and the First Digit Problem. Fundamenta Mathematicae, 65(1): 33-42.

Charbonneau, F. - Lachance, R. (2015): Rapport final de la Commission d'enquête sur l'octroi et la gestion des contrats publics dans l'industrie de la construction (Final Report of the Commission of Inquiry on the Awarding and Management of Public Contracts in the Construction Industry). Québec. www.ceic.gouv.qc.ca/fileadmin/Fichiers_client/fichiers/Rapport_final/ Rapport_final_CEIC_Integral_c.pdf.

Clippe, P. - Ausloos, M. (2012): Benford's Law and Theil Transform of Financial Data. Physica A: Statistical Mechanics and Its Applications, 391(24): 6556-6567. 
Cohen, D. I. (1976): An Explanation of the First Digit Phenomenon. Journal of Combinatorial Theory, Series A, 20(3): 367-370.

Commission regulation (EC) No 250/2009 of 11 March 2009 implementing Regulation (EC) No 295/2008 of the European Parliament and of the Council as regards the definitions of characteristics, the technical format for the transmission of data, the double reporting requirements for NACE Rev.1.1 and NACE Rev.2 and derogations to be granted for structural business statistics.

Davis, B. (1976): Some Remarks on Initial Digits. Fibonacci Quartely, 14(1): 13-14.

De Ceuster, M. J. - Dhaene, G. - Schatteman, T. (1998): On the Hypothesis of Psychological Barriers in Stock Markets and Benford's Law. Journal of Empirical Finance, 5(3): 263-279.

Deleanu, I. S. (2017): Do Countries Consistently Engage in Misinforming the International Community about Their Efforts to Combat Money Laundering? Evidence Using Benford's Law. PloS ONE, 12(1): e0169632.

Della Porta, D. - Vannucci, A. (2016): The Hidden Order of Corruption: An Institutional Approach. London: Routledge.

Diaconis, P. (1973): Limits of Measures of the Integers with Application to Random Number Generators and the Distribution of Leading Digits. Memorandum, NS-211, Department of Statistics, Harvard University.

Diekmann, A. (2007): Not the First Digit! Using Benford's Law to Detect Fraudulent Scientific Data. Journal of Applied Statistics, 34(3): 321-329.

Duncan, R. L. (1969): Note on the Initial Digit Problem. Fibonacci Quarterly, 7(5): 474-475.

Durtschi, C. - Hillison, W. - Pacini, C. (2004): The Effective Use of Benford's Law to Assist in Detecting Fraud in Accounting Data. Journal of Forensic Accounting, 5(1): 17-34.

Flehinger, B. J. (1966): On the Probability That a Random Integer Has Initial Digit A. The American Mathematical Monthly, 73(10): 1056-1061.

Fourth Council Directive, 78/660/EEC of 25 July 1978.

Fu, D. - Shi, Y. Q. - Su, W. (2007): A Generalized Benford's Law for JPEG Coefficients and Its Applications in Image Forensics. In: Electronic Imaging, vol. 6505, International Society for Optics and Photonics, San Jose, CA, USA: 65051L DOI: 10.1117/12.704723.

Furlan, L. V. (1946): Das Harmoniegesetz der Statistik: Eine Untersuchung "über die metrische Interdependenz der sozialen Erscheinungen (The Law of Harmony in Statistics: References 80 Investigations of the Metrical Interdependence of Social Phenomena), volume 2, Beihefte zum Assekuranzjahrbuch. Basel, Switzerland: Verlag für Recht und Gesellschaft A. G.

Gini, C. (1957): Sulla frequenza delle cifre iniziali dei numeri osservati (On the Frequency of Initial Digits of Observed Numbers). Bulletin de l'Institut International de Statistique, 35(2): 57-76.

Glancy, F. H. - Yadav, S. B. (2011): A Computational Model for Financial Reporting Fraud Detection. Decision Support Systems, 50(3): 595-601.

Gomes da Silva, C. - Carreira, P. M. (2013): Selecting Audit Samples Using Benford's Law. Auditing: A Journal of Practice - Theory, 32(2): 53-65.

Hake, E. R. (2005): Financial Illusion: Accounting for Profits in an Enron World. Journal of Economic Issues, 39(3): 595-611.

Herzel, A. (1957): Sulla distribuzione delle cifre iniziali dei numeri statistici (On the Frequency of Initial Digits of Statistical Numbers). Atti dell XV e XVII Riunione, Societa Italiana di Statistica, Roma, pp. 205-228.

Hill, T. P. (1988): Random-Number Guessing and the First Digit Phenomenon. Psychological Reports, 62(3): 967-971.

Hogan, C. E. - Rezaee, Z. - Riley, R. A. - Velury, U. K. (2008): Financial Statement Fraud: Insights from the Academic Literature. Auditing: A Journal of Practice - Theory, 27(2): 231-252. 
Jamain, D. (2011): Benford's Law. Dissertation Report. Department of Mathematics, Imperial College, London.

Joenssen, D. W. (2013): Two Digit Testing for Benford's Law. Proceedings of the 59th ISI World Statistics Congress, 25-30 August 2013, Hong Kong (Session CPS021): 3881-3886.

Joksimović, D. - Knežević, G. (2016): Benford's Law and the Analysis of the Numerical Data. In: Simović, D. (ed.): International Scientific Conference "Archibald Reiss Days". Proceedings of International Significance, Academy of Criminalistic and Police Studies, Belgrade, 10 - 11 March 2016, pp. 293-306.

Joksimović, D. - Knežević, G. - Pavlović, V. - Ljubić, M. - Surovy, V. (2017): Some Aspects of the Application of Benford's Law in the Analysis of the Data Set Anomalies. In: Knowledge Discovery in Cyberspace: Statistical Analysis and Predictive Modeling. New York: Nova Science Publishers, pp. 85-120.

Joyce, B. P. (2001): E-diligence: Money Laundering Risks in the Electronic Arena. Journal of Money Laundering Control, 5(2): 146-149.

Karavardar, A. (2014): Benford's Law and an Analysis in Istanbul Stock Exchange (BIST). International Journal of Business and Management, 9(4): 160-172.

Kumar, K. - Bhattacharya, S. (2007): Detecting the Dubious Digits: Benford's Law in Forensic Accounting. Significance, 4(2): 81-83.

Ljubić, M. - Pavlović, V. (2016): The Role of the Accounting Profession in Prevention and Detection of Financial Statement Fraud. In: Simović, D. (ed.): International Scientific Conference “Archibald Reiss Days". Proceedings of International Significance, Academy of Criminalistic and Police Studies, Belgrade, 10 - 11 March 2016, pp. 87-100.

Marai, A. - Pavlović, V. (2013): Earnings Management vs Financial Reporting Fraud - Key Features for Distinguishing. Facta universitatis - series: Economics and Organization, 10(1): 39-47.

Martin, J. (2017): How Strong Forensic Data Analytics Capabilities Allow Companies and Contract Owners to Catch Bidding Fraud. KPMG Forensic Focus, 29 March 2017. https://assets.kpmg. $\mathrm{com} / \mathrm{content} / \mathrm{dam} / \mathrm{kpmg} / \mathrm{ca} / \mathrm{pdf} / 2017 / 03 / \mathrm{ca}$-forensic-focus-fda-against-bidding-fraud.pdf

McAlister, D. (1879): Law of Frequency. Nature, 20(510): 337.

McDaniel, L. S. - Kinney, W. R. (1995): Expectation-Formation Guidance in the Auditor's Review of Interim Financial Information. Journal of Accounting Research, 33(1): 59-76.

Michalski, T. - Stoltz, G. (2013): Do Countries Falsify Economic Data Strategically? Some Evidence That They Might. Review of Economics and Statistics, 95(2): 591-616.

Mir, T. A. - Ausloos, M. - Cerqueti, R. (2014): Benford's Law Predicted Digit Distribution of Aggregated Income Taxes: The Surprising Conformity of Italian Cities and Regions. The European Physical Journal B, 87(11): 261.

Moser, L. - Macon, N. (1950): On the Distribution of First Digits of Powers. Scripta Mathematica, 16: $290-292$.

Newcomb, S. (1881): Note on the Frequency of Use of the Different Digits in Natural Numbers. American Journal of Mathematics, 4(1): 39-40.

Ngai, E. W. T. - Hu, Y. - Wong, Y. H. - Chen, Y. - Sun, X. (2011): The Application of Data Mining Techniques in Financial Fraud Detection: A Classification Framework and an Academic Review of Literature. Decision Support Systems, 50(3): 559-569.

Nigrini, M. J. (2017): Audit Sampling Using Benford's Law: A Review of the Literature with Some New Perspectives. Journal of Emerging Technologies in Accounting, 14(2): 29-46.

Pinkham, R. S. (1961): On the Distribution of First Significant Digits. The Annals of Mathematical Statistics, 32(4): 1223-1230.

Raimi, R. (1976): The First Digit Problem. The American Mathematical Monthly, 83(7): 521-538. 
Rose, J. M. (2007): Attention to Evidence of Aggressive Financial Reporting and Intentional Misstatement Judgments: Effects of Experience and Trust. Behavioral Research in Accounting, 19(1): 215-229.

Shi, J. - Ausloos, M. - Zhu, T. (2018): Benford's Law First Significant Digit and Distribution Distances for Testing the Reliability of Financial Reports in Developing Countries. Physica A: Statistical Mechanics and its Applications, 492: 878-888.

Smith, F. (1964): Measuring Risk on Consumer Instalment Credit. Management Science, 11(2): $327-340$.

Spasić, D. (2016): Recent Changes in Regulatory Framework for Financial Reporting in Serbia A Step Backward in Internationalization of Business? In: Okręglicka, M. - Gorzeń-Mitka, I. - Lemańska-Majdzik, A. - Sipa, M. - Skibiński, A. (eds): Proceedings of the 1st International Conference Contemporary Issues in Theory and Practice of Management 2016. Częstochowa: Wydawnictwo Wydziału Zarządzania Politechniki Częstochowskiej, pp. 403-409.

Stephens, M. A. (1970): Use of the Kolmogorov-Smirnov, Cramér-Von Mises and Related Statistics without Extensive Tables. Journal of the Royal Statistical Society, Series B (Methodological), 32(1):115-122.

Stoessiger, R. (2013): Benford's Law and Why the Integers Are Not What We Think They Are: A Critical Numeracy of Benford's Law. Australian Senior Mathematics Journal, 27(1): 29-46.

The Serbian Business Registers Agency (SBRA) webpage: www.apr.gov.rs.

Tóth, I. J. - Hajdu, M. (2016): Competitive Intensity and Corruption Risks in the Hungarian Public Procurement 2009-2015. Proceeding of the Corruption Research Center, Budapest, pp. 1-7.

Whitney, R. E. (1972): Initial Digits for the Sequence of Primes. The American Mathematical Monthly, 79(2): 150-152.

Zhou, W. - Kapoor, G. (2011): Detecting Evolutionary Financial Statement Fraud. Decision Support Systems, 50(3): 570-575. 


\section{APPENDIX}

Proof 1. (Based on: Jamain 2011; Joksimović et al. 2017)

We can prove that from Definition 1 follows Definition 2.

Let the function of the probability distribution of mantissa of random variable $\boldsymbol{X}$, $\boldsymbol{M}(\boldsymbol{X})$, in the base $B>1$, satisfy the law $P\left(M_{B}(x) \leq m\right)=\log _{B} m$, were $m \in[1, B)$. Then, for the probability distribution of the first $\boldsymbol{k}$ significant digits in the realization of random variable $\boldsymbol{X},\left(C_{j}\right)_{j=1,2, \ldots, k},\left(k \in N^{*}\right)$, satisfies:

$$
\begin{aligned}
& P\left(C_{1}=c_{1}, C_{2}=c_{2}, \ldots, C_{k}=c_{k}\right)=P\left(\sum_{i=1}^{k} c_{i} B^{1-i} \leq M_{B}(x)<\sum_{i=1}^{k-1} c_{i} B^{1-i}+\left(c_{k}+1\right) B^{1-k}\right) \\
& =\log _{B}\left(\frac{\sum_{i=1}^{k-1} c_{i} B^{1-i}+\left(c_{k}+1\right) B^{1-k}}{\sum_{i=1}^{k} c_{i} B^{1-i}}\right)=\log _{B}\left(1+\frac{1}{\sum_{i=1}^{k} B^{k-i} c_{i}}\right)
\end{aligned}
$$

Let us now prove that from Definition 2 follows Definition 1.

So in the base $B>1$, the probability distribution of the first $\boldsymbol{k}$ significant digits, the realization of random variable $\mathbf{X},\left(C_{j}\right)_{j=1,2, \ldots, k},\left(k \in N^{*}\right)$, satisfies the following law:

$$
P\left(C_{1}=c_{1}, C_{2}=c_{2}, \ldots, C_{k}=c_{k}\right)=\log _{B}\left(1+\frac{1}{\sum_{i=1}^{k} B^{k-i} c_{i}}\right)
$$

where $c_{1} \in(1,2, \ldots, B-1), c_{j>1} \in(0,1,2, \ldots, B-1)$.

Let $m \in[1, B]$ be comprised of only one digit. Respectively, $m \in[1,2, \ldots, B-1]$.

Then, if $\mathrm{m}=1$, because of the infinity the following is satisfied

$$
P\left(M_{B}(x) \leq m\right)=P\left(M_{B}(x)<m\right)=P\left(M_{B}(x)<1\right)=0=\log _{B} 1=\log _{B} m,
$$

because $M_{B}(x) \subset[1, B)$.

If $m=c_{1} \neq 1$, respectively $m \in[2, \ldots, B-1]$, then it satisfies:

$P\left(M_{B}(x) \leq m\right)=P\left(M_{B}(x) \leq c_{1}\right)=P\left(M_{B}(x)<c_{1}\right)=P\left(C_{1} \leq c_{1}-1\right)=\sum_{l=1}^{c_{1}-1} P\left(C_{1}=l\right)$.

From (1) follows $P\left(C_{1}=l\right)=\log _{B}\left(1+\frac{1}{l}\right)$, that is why we have the following
expression: expression:

$$
P\left(M_{B}(x) \leq m\right)=\sum_{l=1}^{c_{1}-1} \log _{B}\left(1+\frac{1}{l}\right)=\log _{B}\left(\prod_{l=1}^{c_{1}-1}\left(\frac{l+1}{l}\right)\right)=\log _{B} c_{1}=\log _{B} m .
$$


Let now $m \in[1, B]$ be comprised of $\boldsymbol{k}$ digits, where $\left(k \in \mathrm{N}^{*}\right), m=c_{1} c_{2} \ldots c_{k}$ in the base $B>1$. Therefore, $m=\sum_{i=1}^{k} \frac{c_{i}}{B^{i-1}}$. Now it is

$$
\begin{aligned}
& P\left(M_{B}(x) \leq m\right)=P\left(C_{1} \leq c_{1}-1\right)+P\left(C_{1}=c_{1}, C_{2} \leq c_{2}-1\right)+\ldots \\
& +P\left(C_{1}=c_{1}, \ldots, C_{k-1}=c_{k-1}, C_{k} \leq c_{k}-1\right) \\
& =P\left(C_{1} \leq c_{1}-1\right)+\sum_{l=0}^{c_{2}-1} P\left(C_{1}=c_{1}, C_{2}=l\right)+\ldots \\
& +\sum_{l=0}^{c_{k}-1} P\left(C_{1}=c_{1}, \ldots, C_{k-1}=c_{k-1}, C_{k}=l\right) \\
& =\log _{B} c_{1}+\sum_{l=0}^{c_{2}-1} \log _{B}\left(1+\frac{1}{B c_{1}+l}\right)+\ldots+\sum_{l=0}^{c_{k}-1} \log _{B}\left(1+\frac{1}{\left(\sum_{i=1}^{k-1} B^{k-i} c_{i}+l\right)}\right) \\
& =\log _{B} c_{1}+\log _{B}\left(\frac{B c_{1}+c_{2}}{B c_{1}}\right)+\ldots+\log _{B}\left(\frac{\sum_{i=1}^{k} B^{k-i} c_{i}}{\sum_{i=1}^{k-1} B^{k-i} c_{i}}\right)=\log _{B}\left(\frac{\sum_{i=1}^{k} B^{k-i} c_{i}}{B^{k-1}}\right) \\
& =\log _{B}\left(\sum_{i=1}^{k} \frac{c_{i}}{B^{i-1}}\right)=\log _{B} m
\end{aligned}
$$

With this we make formal equivalency of these definitions. 